\title{
Abdominal venous thrombosis presenting in myeloproliferative neoplasm with JAK2 V617F mutation: a case report
}

\author{
Naveen Pemmaraju ${ }^{*}$, James Peter Hamilton², Andrew M Cameron² ${ }^{2}$ Stephen Sisson ${ }^{2}$ and Alison R Moliterno ${ }^{2}$
}

\begin{abstract}
Introduction: An unprovoked thombotic event in a patient is cause for further evaluation of an underlying hypercoaguable state. The investigation should include a thorough search, including checking for a variety of known inherited and acquired hypercoaguble states (protein C or S deficiency, anti-phospholipid antibodies, and anti-thrombin III deficiency) and gene mutations that predispose patients to an increased risk of clotting (for example, prothrombin gene 20210 mutation, factor V Leiden, and the JAK2 V617F mutation).

Case presentation: We report the case of a 38-year-old Caucasian woman with spontaneous, unprovoked abdominal venous thrombosis and demonstrate how testing for the JAK2 V617F mutation was useful in unmasking an underlying hypercoaguable state.

Conclusions: JAK2 V617F-positive myeloproliferative neoplasm was diagnosed. This case illustrates the importance of testing for JAK2 V617F in patients presenting with Budd-Chiari syndrome, even in the absence of overt hematologic abnormalities, in order to establish a diagnosis of underlying myeloproliferative neoplasm.
\end{abstract}

\section{Introduction}

An unprovoked thombotic event in a patient is cause for further evaluation of an underlying hypercoaguable state. The investigation should include a thorough search, including checking for a variety of known inherited and acquired hypercoaguble states and gene mutations that predispose patients to an increased risk of clotting. Therefore, the differential diagnosis of underlying etiologies of Budd-Chiari syndrome (BCS) includes the following: myeloproliferative neoplasm (MPN), malignancy, paroxysmal nocturnal hemoglobinuria, antiphospholipid syndrome, sickle cell anemia, and inherited hypercoaguable states, including factor $\mathrm{V}$ Leiden, prothrombin 20210 mutation, and protein $C$ and $S$ and anti-thrombin deficiencies [1].

The MPNs are a related group of diseases that have a common origin of an acquired stem cell or progenitor cell defect that leads to the development of overproliferation of the myeloid series, manifest as essential

\footnotetext{
* Correspondence: npemmaraju@mdanderson.org

'MD Anderson Cancer Center, 1515 Holcombe Boulevard, Houston, TX 77030, USA

Full list of author information is available at the end of the article
}

thrombocytosis (ET), polycythemia vera (PV), or primary myelofibrosis (PMF). In 2005, it was demonstrated that MPNs are connected by an acquired somatic mutation of the JAK2 gene, JAK2 V617F [2], which is found in approximately $95 \%$ of patients with PV and in $50 \%$ of patients with ET or PMF.

\section{Case presentation}

A 38-year-old Caucasian woman presented to our hospital with two months of epigastric abdominal pain associated with bloating. She denied nausea or vomiting, history of acid reflux, constipation, or diarrhea. She had no known trauma. She affirmed complaints of fatigue and decreased appetite but denied fevers, chills, night sweats, or weight loss. She denied a history of liver or blood disorders.

The initial evaluation revealed a jaundiced young woman with abdominal ascites and trace lower-extremity edema. Laboratory studies revealed elevated levels of gamma glutamyl transferase (GGT), total bilirubin, and CA-125. A computed tomography (CT) scan with oral and intravenous contrast of the abdomen and pelvis was performed, demonstrating a heterogeneous

\section{Ciomed Central}


appearance of the liver and caudate lobe hypertrophy, ascites, and a cystic mass in the right ovary. The liver abnormalities described were thought to be consistent with diffuse metastatic involvement of the liver, and the ovaries were thought to be a possible primary source. Our patient then underwent laparoscopic oopherectomy and liver biopsy to evaluate for underlying malignancy. No evidence of either ovarian or hepatic malignancy was found, but the liver biopsy revealed fibrous obliteration of the central hepatic veins and patchy areas of sinusoidal dilatation diagnostic of hepatic vein obstruction, or BCS. A triphasic CT scan of the liver with three-dimensional reconstruction confirmed occlusion of the hepatic veins and associated ascites, splenomegaly, and abdominal varices.

Our patient's medical history was notable for one episode of unexplained syncope one year prior and migraine with aura. Medications included warfarin and aspirin. Our patient was married and lived with her husband. She worked as a busy executive, frequently taking international flights. She had never smoked and she drank one or two glasses of wine per week. The only family history of a thrombosis was in a paternal aunt with a deep vein thrombosis in the setting of a long car ride. Our patient had no family history of cancer or other blood disorders.

Laboratory findings revealed a white blood cell count of $3640 \mathrm{~K} / \mu \mathrm{L}$, hemoglobin of $11.1 \mathrm{~g} / \mathrm{dL}$, mean corpuscular volume $(\mathrm{MCV})$ of $80 \mathrm{fL}$, and a platelet count of $252,000 \mathrm{~K} / \mu \mathrm{L}$. Erythropoietin level was $22 \mathrm{mIU} / \mathrm{mL}$ (normal is 4.1 to 19.5 ), international normalized ratio was 1.4 on warfarin therapy, ammonia $45 \mathrm{Umol} / \mathrm{L}$ (10 to $47 \mathrm{Umol} / \mathrm{L}$ ), total bilirubin $3.1 \mathrm{mg} / \mathrm{dL}$, direct bilirubin 0.6, albumin $3.7 \mathrm{~g} / \mathrm{dL}$, and alkaline phosphate $158 \mathrm{IU} / \mathrm{L}$. Alanine aminotransferase and aspartate aminotransferase were normal. GGT was elevated to $120 \mathrm{U} / \mathrm{L}$ (12 to $48 \mathrm{U} / \mathrm{L}$ ). CA-125 was $55 \mathrm{U} / \mathrm{mL}$ (normal is less than 35 $\mathrm{U} / \mathrm{mL}$ ). Liver biopsy results showed central hepatic veins with pericentral fibrosis and mild portal fibrosis and patchy areas of moderate sinusoidal dilatation consistent with chronic BCS.

Our patient was evaluated for a hypercoaguable state, including tests for lupus anticoagulant and anti-phospholipid antibodies, factor $\mathrm{V}$ Leiden, and prothombin 20210 mutation. The results of these tests were negative. Levels of anti-thrombin and protein $C$ and $S$ were normal. The result of one test was found from the hypercoaguable workup to be positive: JAK2 V617F mutation with an allele percentage of $36 \%$. Complete blood counts obtained in the five years prior to her diagnosis were notable for thrombocytosis (Table 1).

\section{Discussion}

On the basis of the new-onset BCS combined with the finding of the JAK2 V617F mutation, our patient's condition was diagnosed as an underlying chronic MPN. Thromboses, including abdominal vein thromboses, constitute a major etiology of morbidity and mortality in MPN [3]. MPN now constitutes the most common cause of abdominal venous thromboses, accounting for approximately $50 \%$ of BCS cases and $25 \%$ of portal vein thromboses [4]. A recent study demonstrated MPN to be the most prevalent underlying condition (49\%) in a series of 163 incident cases of BCS [1]. In most of these patients, portal hypertension was a typical feature. This becomes important because it may help to explain the surprisingly low or normal blood counts observed in BCS JAK2 V617F-positive patients; the subsequent hemodilution and hypersplenism resulting from the portal hypertension may decrease the actual hemoglobin and other blood cell counts, making the diagnosis of MPN quite challenging in many cases [4]. Masking of the MPN by subsequent hemodilution from portal hypertension or even from hepatic dysfunction is evident in our patient, in whom the platelet count

Table 1 Complete blood counts in a patient with JAK2 V617F-associated Budd-Chiari syndrome

\begin{tabular}{|c|c|c|c|c|}
\hline Date & Hemoglobin, g/dL & $W B C s, K / \mu L$ & Platelets, $\mathrm{K} / \mu \mathrm{L}$ & Clinical events \\
\hline Dec. 9, 2002 & 11.3 & 4.1 & 349 & \\
\hline Dec. 19, 2002 & 12.9 & 6.6 & 416 & \\
\hline Jan. 10, 2006 & 13.8 & 8.6 & 522 & \\
\hline Dec. 27, 2007 & 13.9 & 6.9 & 354 & Symptoms of BCS \\
\hline Jan. 7, 2008 & 12.5 & 5.5 & 379 & Post-oophorectomy \\
\hline March 25, 2008 & 13.5 & 4.7 & 261 & Post-TIPS \\
\hline April 29, 2008 & 11.1 & 3.6 & 252 & Follow-up visit \\
\hline July 29, 2008 & 12.5 & 3.5 & 239 & Follow-up visit \\
\hline Sept. 15, 2009 & 13.2 & 4.7 & 287 & Follow-up visit \\
\hline May 4, 2010 & 14.1 & 5.4 & 293 & Follow-up visit \\
\hline June 3, 2011 & 13.3 & 5.2 & 285 & Follow-up visit \\
\hline
\end{tabular}

Normal ranges of hemoglobin, white blood cells (WBCs), and platelets are 12 to $15 \mathrm{~g} / \mathrm{dL}, 4.5$ to $11 \mathrm{~K} / \mu \mathrm{L}$, and 150 to $450 \mathrm{~K} / \mu \mathrm{L}$, respectively. BCS, Budd-Chiari syndrome; TIPS, transjugular intrahepatic porto-systemic shunt. 
normalized from the previously mild elevation evident in the years before her BCS diagnosis (Table 1). Several groups have hypothesized that endothelial cell (EC) dysfunction may contribute to the prothrombotic state in MPN. In a seminal study, Sozer and colleagues [5] demonstrated that the JAK2 V617F mutation was present in the ECs from venules of liver biopsy specimens obtained from two patients with BCS and PV, suggesting that ECs in PV are involved in the malignant process and contribute to the prothrombotic state found in this disorder.

It has been suspected for decades that primary, occult MPN may play a role in the prevalence of BCS, especially in young women. One study demonstrated that erythroid colony formation in the absence of erythropoietin, a reliable indicator of MPN in the pre-JAK2 $V 617 F$ era, was present in 16 out of 20 patients with BCS, most of whom were young women (18 to 45 years old) [6]. The authors concluded, some 20 years prior to the elucidation of the JAK2 V617F mutation, that primary MPN is a major cause of BCS in young women. Many cases labeled as idiopathic BCS have been subsequently found to be secondary to underlying myeloproliferative disease upon $J A K 2 V 617 F$ testing [7]. In the literature reported to date, the largest series relating $J A K 2$ V617F mutation status to abdominal venous thrombosis showed that JAK2 V617F-associated BCS was predominantly a disease of young women, that it was associated with relatively low JAK2 V617F allele burdens, and that the majority of the patients did not have additional identified hypercoagulable risk factors, all features common to our patient [4]. Also, the most common risks for thrombotic disease in MPN are older age (> 60 years), elevated white cell count, and prior thrombotic events [8], none of which applies to either our patient or the MPN BCS patients at large [4]. The discrepancy between the absence of traditional MPN thrombotic risk factors and the low JAK2 V617F allele burdens in the patients with BCS indicates that other important risk factors for this devastating presentation, particularly relevant to young women with MPN, remain undefined [9]. It is interesting to note that our patient's JAK2 V617 allele burden at diagnosis measured only $36 \%$. JAK2 V617F allele burdens are lower in women in comparison with men, suggesting that gender is an important modifier of disease phenotype and may in part account for differences in disease presentation and complications between men and women with JAK2 V617F-positive MPNs $[3,10]$.

It is important to note that, because JAK2 V617F is present in $95 \%$ of patients with PV but only in approximately $50 \%$ of patients with ET or PMF, a negative $J A K 2$ V617F study should not by itself preclude the diagnosis of an underlying MPN. In such cases, further investigation, including a bone marrow biopsy, should be sought as part of a complete workup.

\section{Conclusions}

Our patient's condition was diagnosed as JAK2 V617Fpositive MPN, most consistent with ET (Table 1). She subsequently underwent a transjugular intrahepatic porto-systemic shunt (TIPS) placement to decompress her hepatic obstruction and this was followed by indefinite warfarin-based anticoagulation. Her clinical status and blood counts have been stable in the three years since her TIPS procedure (Table 1), and her hepatic function remains excellent. This case illustrates the importance of testing for JAK2 V617F in patients presenting with BCS, even in the absence of overt hematologic abnormalities, in order to establish a diagnosis of underlying MPN. Although molecular testing with JAK2 is rather specific to the MPN classification, it alone cannot specify which MPN the patient harbors $[11,12]$. Therefore, further studies, including red cell mass, regular complete blood cell counts, and assessment of the JAK2 V617F allele percentage over time, may be indicated to further aid in the individual MPN diagnosis of our patient [10]. It is important to recognize that CA125 is not a reliable screening test for the diagnosis of ovarian cancer in pre-menopausal woman. In addition, as in this case, CA-125 can be elevated in the presence of liver disease and can be a sensitive marker of ascites [13]. Finally, non-invasive imaging is of critical importance in the diagnostic evaluation of abdominal vein thrombosis, and the majority of cases are identified by Doppler ultrasound. In some instances, high-quality multi-phasic examinations of the liver are often needed to confirm the diagnosis of BCS.

\section{Consent}

Written informed consent was obtained from the patient for publication of this manuscript and accompanying images. A copy of the written consent is available for review by the Editor-in-Chief of this journal.

\section{Abbreviations}

BCS: Budd-Chiari syndrome; CT: computed tomography; EC: endothelial cell; ET: essential thrombocytosis; GGT: gamma glutamyl transferase; MPN: myeloproliferative neoplasm; PMF: primary myelofibrosis; PV: polycythemia vera; TIPS: transjugular intrahepatic porto-systemic shunt.

\section{Author details}

${ }^{1}$ MD Anderson Cancer Center, 1515 Holcombe Boulevard, Houston, TX 77030, USA. ${ }^{2} J o h n s$ Hopkins Hospital, 600 North Wolfe Street, Baltimore, MD 21287, USA.

\section{Authors' contributions}

NP and ARM helped to design and write the manuscript and to analyze and interpret the hematologic and internal medicine aspects of the patient data from this case. SS helped to analyze and interpret the hematologic and internal medicine aspects of the patient data from this case. JPH and AMC 
analyzed and assisted with the gastrointestinal and hepatologic interpretation of data from this case. All authors read and approved the final manuscript.

\section{Competing interests}

The authors declare that they have no competing interests.

Received: 14 October 2011 Accepted: 5 April 2012

Published: 5 April 2012

\section{References}

1. Darwish Murad S, Plessier A, Hernandez-Guerra M, Fabris F, Eapen CE, Bahr MJ, Trebicka J, Morard I, Lasser L, Heller J, Hadengue A, Langlet P, Miranda H, Primignani M, Elias E, Leebeek FW, Rosendaal FR, GarciaPagan JC, Valla DC, Janssen HL, EN-Vie (European Network for Vascular Disorders of the Liver): Etiology, management, and outcome of the BuddChiari syndrome. Ann Intern Med 2009, 151:167-175.

2. Baxter EJ, Scott LM, Campbell PJ, East C, Fourouclas N, Swanton S, Vassiliou GS, Bench AJ, Boyd EM, Curtin N, Scott MA, Erber WN, Green AR, Cancer Genome Project: Acquired mutation of the tyrosine kinase JAK2 in human myeloproliferative disorders. Lancet 2005, 365:1054-1061.

3. Stein BL, Rademaker A, Spivak JL, Moliterno AR: Gender and vascular complications in the JAK2 V617F-positive myeloproliferative neoplasms. Thrombosis 2011, 2011:874146.

4. Kiladjian JJ, Cervantes F, Leebeek FW, Marzac C, Cassinat B, Chevret S, Cazals-Hatem D, Plessier A, Garcia-Pagan JC, Darwish Murad S, Raffa S, Janssen HL, Gardin C, Cereja S, Tonetti C, Giraudier S, Condat B, Casadevall N, Fenaux P, Valla DC: The impact of JAK2 and MPL mutations on diagnosis and prognosis of splanchnic vein thrombosis: a report on 241 cases. Blood 2008, 111:4922-4929.

5. Sozer S, Fiel Ml, Schiano T, Xu M, Mascarenhas J, Hoffman R: The presence of JAK2V617F mutation in the liver endothelial cells of patients with Budd-Chiari syndrome. Blood 2009, 113:5246-5249.

6. Valla D, Casadevall N, Lacombe C, Varet B, Goldwasser E, Franco D, Maillard JN, Pariente EA, Leporrier M, Rueff B, et al: Primary myeloproliferative disorder and hepatic vein thrombosis. A prospective study of erythroid colony formation in vitro in 20 patients with BuddChiari syndrome. Ann Intern Med 1985, 103:329-334.

7. Patel RK, Lea NC, Heneghan MA, Westwood NB, Milojkovic D, Thanigaikumar M, Yallop D, Arya R, Pagliuca A, Gäken J, Wendon J, Heaton ND, Mufti GJ: Prevalence of the activating JAK2 tyrosine kinase mutation V617F in the Budd-Chiari syndrome. Gastroenterology 2006, 130:2031-2038.

8. Carobbio A, Finazzi G, Antonioli E, Guglielmelli P, Vannucchi AM, Delaini F, Guerini V, Ruggeri M, Rodeghiero F, Rambaldi A, Barbui T: Thrombocytosis and leukocytosis interaction in vascular complications of essential thrombocythemia. Blood 2008, 112:3135-3137.

9. Pemmaraju N, Moliterno AR, Williams DM, Rogers O, Spivak JL: The quantitative JAK2 V617F neutrophil allele burden does not correlate with thrombotic risk in essential thrombocytosis. Leukemia 2007, 21:2210-2212.

10. Stein BL, Williams DM, Wang NY, Rogers O, Isaacs MA, Pemmaraju N, Spivak JL, Moliterno AR: Sex differences in the JAK2 V617F allele burden in chronic myeloproliferative disorders. Haematologica 2010, 95:1090-1097.

11. Spivak JL, Moliterno AR, Silver RT: Case 15-2006: the Budd-Chiari syndrome and V617F mutation in JAK2. N Engl J Med 2006, 355:737, author reply 738 .

12. Moliterno AR, Williams DM, Rogers O, Isaacs MA, Spivak JL: Phenotypic variability within the JAK2 V617F-positive MPD: roles of progenitor cell and neutrophil allele burdens. Exp Hematol 2008, 36:1480-1486.

13. Zuckerman E, Lanir A, Sabo E, Rosenvald-Zuckerman T, Matter I, Yeshurun D, Eldar S: Cancer antigen 125: a sensitive marker of ascites in patients with liver cirrhosis. Am J Gastroenterol 1999, 94:1613-1618.

doi:10.1186/1752-1947-6-102

Cite this article as: Pemmaraju et al:: Abdominal venous thrombosis presenting in myeloproliferative neoplasm with JAK2 V617F mutation: a case report. Journal of Medical Case Reports 2012 6:102.

\section{Submit your next manuscript to BioMed Central and take full advantage of:}

- Convenient online submission

- Thorough peer review

- No space constraints or color figure charges

- Immediate publication on acceptance

- Inclusion in PubMed, CAS, Scopus and Google Scholar

- Research which is freely available for redistribution

Submit your manuscript at www.biomedcentral.com/submit 